\title{
Adubação de precisão em plantio de Eucalyptus brassiana $x$ Eucalyptus grandis na Amazônia Oriental
}

Entender a eficiência vegetal em converter os nutrientes absorvidos em biomassa são indispensáveis para programas nutricionais de precisão. 0 objetivo deste trabalho foi avaliar a necessidade nutricional no estágio inicial de desenvolvimento de um plantio clonal do híbrido de eucalipto. Foram instaladas 6 parcelas de $750 \mathrm{~m}^{2}$, contendo 100 plantas. Cada parcela representou um tratamento com níveis pré-estabelecidos de 1 a 6 , consistindo no máximo biológico, sendo os tratamentos: $0 \%, 50 \%, 75 \%, 100 \%, 125 \%$ e $150 \%$ de adubação. Para todas as variáveis analisadas, os tratamentos que apresentaram diferenças foram: T4 e o T3. Para as taxas de crescimento, os melhores resultados foram para o T4, com coeficiente angular 0,5379; 0, 0789 e 0, 5888 para as variáveis altura, diâmetro do coleto e diâmetro de copa respectivamente. O T3 com coeficiente angular de 0, 4928 para altura, 0, 0737 para o diâmetro do coleto e 0, 4992 para o diâmetro de copa. Quanto ao ganho o T4 foi o que obteve maior ganho em altura (30\%), diâmetro do coleto (8\%) e diâmetro de copa (35\%). Assim, o híbrido Eucalyptus brassiana S.T. Blake X Eucalyptus grandis W. Hill ex Maiden, apresentou desenvolvimento inicial diferenciado entre os níveis de adubação testados.

Palavras-chave: Adubação mineral; Desenvolvimento; Eficiência nutricional.

\section{Precision fertilization in planting of Eucalyptus brassiana $x$ Eucalyptus grandis in the Eastern Amazon}

\begin{abstract}
Understanding plant efficiency in converting the nutrients absorbed into biomass is essential for precision nutritional programs. The objective of this work was to evaluate the nutritional need in the initial stage of development of a clonal planting of the eucalyptus hybrid. 6 plots of $750 \mathrm{~m}^{2}$ were installed, containing 100 plants. Each plot represented a treatment with pre-established levels from 1 to 6 , consisting of the maximum biological, with the treatments: $0 \%, 50 \%, 75 \%, 100 \%$, $125 \%$ and $150 \%$ fertilization. For all variables analyzed, the treatments that showed differences were: T4 and T3. For growth rates, the best results were for T4, with slope 0, 5379; 0, 0789 and 0, 5888 for the variables height, stem diameter and crown diameter respectively. The T3 with an angle coefficient of 0.4928 for height, 0.0737 for the diameter of the collection and 0.4992 for the crown diameter. As for the gain, T4 was the one that obtained the highest gain in height ( $30 \%$ ), diameter of the stem (8\%) and crown diameter (35\%). Thus, the hybrid Eucalyptus brassiana S.T. Blake X Eucalyptus grandis W. Hill ex Maiden, presented initial development differentiated between the fertilization levels tested.
\end{abstract}

Keywords: Mineral fertilization, Development, Nutritional efficiency.

Topic: Ciências Florestais

Reviewed anonymously in the process of blind peer
Received: 02/10/2020

Approved: $\mathbf{2 0 / 1 1 / 2 0 2 0}$
Jonas Elias Castro da Rocha (1D)

Universidade Federal Rural da Amazônia, Brasil http://lattes.cnpq.br/2036944192394761 http://orcid.org/0000-0002-0255-087X jonas.castro@ufra.edu.br

Sebastião Rodrigo do Remédio Souza de Oliveira (D)

Universidade Federal Rural da Amazônia, Brasil http://lattes.cnpq.br/1942305959879108 http://orcid.org/0000-0002-9498-8237 rodrigosouza6789@gmail.com

Gustavo Aires Sarmanho

Universidade Federal Rural da Amazônia, Brasil http://lattes.cnpq.br/9312982036441819 http://orcid.org/0000-0002-2516-6248 gustavosarmanho1234@gmail.com

\section{Aurélio de Sousa Mendes \\ Universidade Federal Rural da Amazônia, Brasi \\ http://lattes.cnpq.br/2518485872417978 http://orcid.org/0000-0002-3197-6351 aureliomendes09@gmail.com \\ Gilson Sergio Bastos de Matos (iD \\ Universidade Federal Rural da Amazônia, Brasil \\ http://lattes.cnpq.br/3156316891886067 http://orcid.org/0000-0002-0846-0314 \\ gilsonsbm@gmail.com \\ Luis de Souza Freitas (DD) \\ Universidade Federal Rural da Amazônia, Brasil \\ http://lattes.cnpq.br/0747504282703764 http://orcid.org/0000-0003-2321-5269 luis.freitas@ufra.edu.br}

Marcos André Piedade Gama (D)
Universidade Federal Rural da Amazônia,
Brasil
http:///attes.cnpq.br/3991808809325751
$\frac{\text { http://orcid.org/0000-0001-6320-1502 }}{\text { marcos.andre@ufra.edu.br }}$
Francisco de Assis Oliveira
Universidade Federal Rural da Amazônia,
Brasil
http://lattes.cnpq.br/4380083085706495
http://orcid.org/0000-0002-3872-8342
fdeassis@gmail.com
Walmer Bruno Rocha Martins (DD
Universidade Federal Rural da Amazônia,
Brasil
http://lattes.cnpq.br/4159864563302567
http://orcid.org/0000-0001-8795-1703
walmerbruno@gmail.com

Ernandes Macedo da Cunha Neto (ID) Universidade Federal do Paraná, Brasil http://lattes.cnpq.br/9815192447914846 http://orcid.org/0000-0001-6775-0365 netomacedo878@gmail.com
Referencing this:

ROCHA, J. E. C.; OLIVEIRA, S. R. R. S.; SARMANHO, G. A.; MENDES, A. S.; MATOS, G. S. B.; FREITAS, L. S.; GAMA, M. A. P.; OLIVEIRA, F. A.; MARTINS, W. B. R.; CUNHA NETO, E. M.. Adubação de precisão em plantio de Eucalyptus brassiana x Eucalyptus grandis na Amazônia Oriental. Revista Ibero Americana de Ciências Ambientais, v.11, n.6, p.71-85, 2020. DOI: http://doi.org/10.6008/CBPC2179$\underline{6858.2020 .006 .0007}$ 


\section{INTRODUÇÃO}

Atualmente, no Brasil, o Eucalyptus sp. é a espécie florestal exótica cultivada em larga escala, ocupando aproximadamente 5,7 milhões de hectares. Muito se deve a sua capacidade de suprir as demandas das indústrias de produção de papel, celulose, painéis, madeira maciça, laminados, biomassa, entre outros usos (IBÁ, 2019).

Devido a essas questões, o conhecimento dos aspectos ligados à demanda nutricional e a capacidade desses materiais em transformar os nutrientes absorvidos em biomassa é indispensável para a determinação de teores de fertilizantes a serem disponibilizados aos vegetais. A partir desse conhecimento, é possível criar programas de adubação específicos, sobretudo aos fertilizantes sensíveis as propriedades do solo, que são vistos como os de maior interesse nos estágios iniciais de crescimento e desenvolvimento vegetal (BARROS et al., 1990; SANTANA et al., 2002; GOMES et al., 2008).

Esse manejo corrobora nos ajustes nutricionais requeridos pelos povoamentos florestais, com intuito de reduzir custos e aumentar a precisão técnica (PINTO et al., 2011). No entanto, isso só é possível através do uso de pacotes de adubação que considere a influência de fatores bioedafoclimáticos. Dessa forma, é possível obter informações pormenorizadas que auxiliarão nas formulações de fertilizantes minerais em diferentes ou extensas áreas, podendo aludir aspectos limitantes dos nutrientes para as plantas e variações dos volumes produzidos por hectare em plantios florestais (ANDA, 2017).

Geralmente, nas recomendações de adubação utilizadas em plantios, o manejo dos macronutrientes possui maior atenção em relação aos micronutrientes, isto é agravado pelo igual manejo independente da espécie, material genético, tipo de solo e época de plantio. As diferenças na eficiência nutricional entre clones de eucalipto também têm sido observadas em várias pesquisas na literatura, sendo que o entendimento da relação solo e planta pode proporcionar alta eficiência na absorção e utilização de nutrientes. Isso corrobora para a otimização do uso dos fertilizantes no solo e na oferta adequada de nutrientes para as plantas (LIMA et al., 2005; NEVES, 2000; SILVA, 2013; BANDEIRA et al., 2016). No contexto das práticas silviculturais, a adubação tem uma expressiva participação na matriz de custo do empreendimento, correspondendo em aproximadamente $53 \%$ dos custos totais, representando em média $\mathrm{R} \$ 1.677,47$ ha $^{-1}$ (CIPRIANI et al., 2015; SANTOS et al., 2016). Com isso, os estudos na região amazônica que visem técnicas para obtenção de diagnósticos nutricionais em plantios clonais de eucalipto são raros. Além disso, a definição da melhor interação específica dos teores de adubos que seriam mais eficientemente absorvidos e convertidos em biomassa, bem como a redução dos custos dos empreendimentos florestais são pouco estudadas nessa região. Diante do exposto, esta pesquisa tem como objetivo definir o nível de adubação que proporcione o máximo crescimento dendrométrico no estágio inicial de desenvolvimento de um plantio de Eucalyptus brassiana S.T. Blake X Eucalyptus grandis W. Hill Ex Maiden na mesorregião sudeste Paraense. 


\section{MATERIAIS E MÉTODOS}

\section{Caracterização da área de estudo}

O experimento foi realizado na fazenda São Pedro, situada no município de Nova Esperança do Piriá, PA, pertencente ao grupo Transportadora Floresta do Araguaia (TFA). O clima da região é do tipo Am segundo a classificação de Köppen, com temperatura média anual acima de 26 ㄷ e pluviometria anual média de 2.200 mm (ALVARES et al., 2013). O solo da área experimental foi classificado como Latossolo Amarelo de textura argilosa, de acordo com Santos et al. (2018).

\section{Amostragem do solo e preparo da área}

Foram realizadas amostragem do solo para determinação dos atributos físicos e químicos, seguindo a metodologia de Filizola et al. (2006), cada amostra foi composta de cinco amostras simples no interior de cada parcela na profundidade de $20 \mathrm{~cm}$. Após a amostragem de solo a área foi limpa mecanicamente através da roçadeira de arraste e o solo preparado com a operação de subsolagem sem a aplicação de fertilizantes ou aditivos químicos para não alterar os balanços nutricionais testados na pesquisa. Em seguida, foram realizadas as aberturas de covas e posteriormente foram feitos os plantios das mudas. Foram realizadas irrigações diárias para minimizar os efeitos do balanço hídrico negativo, característico do período de estiagem da região.

\section{Tratamentos experimentais}

Seis tratamentos foram instalados e distribuídos sistematicamente em seis parcelas de $750 \mathrm{~m}^{2}$, contendo indivíduos espaçados entre sim nas medidas 3,0 × 2,5 m, perfazendo um total de 100 plantas a serem mensuradas. Os tratamentos foram compostos por dosagens diferentes de fertilizantes, contendo concentrações de macro e micronutrientes minerais em porcentagens diferentes para o híbrido de Eucalyptus brassiana S.T. Blake X Eucalyptus grandis W. Hill ex Maiden, calculado a partir Máximo biológico proposto por Bandeira et al. (2016), para híbridos de Eucalyptus urophylla X Eucalyptus brassiana S.T. Blake manejados na mesorregião sudeste do estado do Pará (Tabela 1). Sendo eles: Controle 1 (T1): com 0\%; Tratamento 2 (T2): com 50\%; Tratamento 3 (T3): com 75\%; Tratamento 4 (T4): com 100\%; Tratamento 5 (T5): com 125\%; Tratamento 6 (T6): com 150\% das quantidades dos nutrientes do Máximo biológico, respectivamente.

Tabela 1: Máximo biológico para o híbrido de Eucalyptus brassiana S.T. Blake X Eucalyptus grandis W. Hill ex Maiden, na mesorregião nordeste paraense.

\begin{tabular}{|c|c|c|c|c|c|c|c|c|c|}
\hline \multicolumn{10}{|c|}{ Máximo biológico (kg ha-1) } \\
\hline Nutrientes & $\mathrm{N}$ & $P$ & $\mathrm{~K}$ & $\mathrm{Ca}$ & $\mathrm{Mg}$ & $\mathrm{S}$ & $B$ & $\mathrm{Zn}$ & $\mathrm{Cu}$ \\
\hline Quantidades & 209,30 & 58,00 & 453,10 & 315,70 & 70,20 & 24,70 & 1,89 & 2,95 & 2,77 \\
\hline
\end{tabular}

Fonte: Adaptada de Bandeira et al. (2016).

A primeira aplicação dos fertilizantes ocorreu dez dias após o plantio das mudas, em que foram aplicadas quantidades proporcionais de cada nutriente, providas pelos fertilizantes NPK (10-27-10), Geox na 
composição (60\% de $\mathrm{CaO}$ e $30 \% \mathrm{MgO}$ ) e Fosfato Natural Reativo (FNR - 32\% de $\mathrm{P}_{2} \mathrm{O}_{5}$ total). A segunda aplicação ocorreu aos três meses após o plantio, sendo utilizado os fertilizantes minerais cloreto de potássio na proporção (NPK 00-00-60), ureia (NPK 45-00-00), sulfato de magnésio, sulfato de cobre, sulfato de zinco e ácido bórico. Cada fertilizante foi devidamente pesado através de uma balança de precisão, e posteriormente separados em sacos plásticos. Em todas as aplicações, os fertilizantes foram dispostos a 15 $\mathrm{cm}$ de distância dos indivíduos, em covetas laterais de aproximadamente $10 \mathrm{~cm}$ de profundidade.

\section{Variáveis analisadas e coleta de dados}

As variáveis coletadas foram à altura total (HT), diâmetro de copa (D Copa) mesuradas através de fita centimétrica e diâmetro do coleto (D Coleto) coletados por meio de um paquímetro digital, posicionado a uma altura de aproximadamente $5 \mathrm{~cm}$ do solo e feita a leitura do diâmetro de cada indivíduo. A primeira coleta de dados ocorreu 10 dias após o plantio das mudas em campo, sendo posteriormente coletados a cada 15 dias.

\section{Delineamento experimental e processamento dos dados}

O delineamento experimental utilizado foi o de blocos ao acaso, com seis tratamentos e quatro blocos para o experimento, totalizando 24 parcelas experimentais. Os dados foram submetidos ao teste de normalidade de Shapiro-Wilk (5\%), as informações que não tiveram a distribuição normal foram normalizados através do uso do logaritmo na base 10, conforme proposto por Sainane (2012), e posteriormente submetidos à análise de variância (ANAVA) e ao teste SNK de comparação múltipla de médias com significância de 5\%.

Para as análises de regressão utilizou-se o Software Statistica trial 13.0 (2020) para os modelos lineares ou linearizados através do método dos mínimos quadrados ordinários. Para a definição da dosagem ideal foram ajustadas equações de regressão e derivadas das equações quadráticas igualando-as a zero para obtenção do ponto máximo, referente a dosagens que exprimem o máximo biológico para o eucalipto. Para a definição da dose de cada nutriente na expectância da produção máxima, foi utilizada a média ponderada entre a expressividade das variáveis analisadas. Para tanto, calculou-se a soma do produto dos valores das três variáveis de cada nutriente das doses máximas recalculadas, dividida pela soma das médias de cada variável dos tratamentos.

\section{RESULTADOS E DISCUSSÃO}

\section{Avaliação da fertilidade do solo}

As médias dos atributos químicos dos nutrientes presentes na área experimental, assim como sua acidez e nível de matéria orgânica (Tabela 2), foram classificados de acordo com estudo os apresentados por Silveira et al. (1999). Esses valores são relevantes para o balanço de nutrientes equilibrado entre a matriz do solo e a demanda de nutrientes específica do vegetal e indicam a necessidade de adubação para o 
desenvolvimento de plantios de alta produtividade (SANA et al., 2014).

Tabela 2: Atributos químicos do solo da área experimental, na Fazenda São Pedro em Nova Esperança do Piriá, PA.

\begin{tabular}{|c|c|c|c|c|c|c|c|c|c|c|}
\hline \multirow{2}{*}{ Profundidade } & $\mathrm{P}$ & $\mathrm{K}$ & $\mathrm{S}$ & $\mathrm{Ca}$ & $\mathrm{Mg}$ & $\mathrm{B}$ & $\mathrm{Zn}$ & $\mathrm{Fe}$ & $\mathrm{Mn}$ & $\mathrm{Cu}$ \\
\hline & \multicolumn{3}{|c|}{$\mathrm{mg} \mathrm{dm}^{-3}$} & \multicolumn{2}{|c|}{ - cmolc dm ${ }^{-3}$ - } & & & $\mathrm{g} \mathrm{dm}^{-3}$ & & \\
\hline $0-20 \mathrm{~cm}$ & 0,9 & 4,9 & 2,9 & 2,17 & 0,72 & 0,35 & 1,1 & 180,07 & 14,2 & 0,3 \\
\hline Status & Baixo & Baixo & Baixo & - & - & - & - & Alto & - & - \\
\hline
\end{tabular}

Em que: Nitrogênio (N); Fósforo (P); Potássio (K); Cálcio (Ca); Magnésio (Mg); Enxofre (S); Boro (B); Cobre (Cu); Zinco (Zn).

As médias encontradas na área do experimento para os valores de $\mathrm{pH}$ em água e em $\mathrm{CaCl}_{2}$ são considerados moderadamente ácido e altamente ácido, respectivamente. Essa acidez pode interferir na disponibilidade de macro e micronutrientes na solução do solo (SIMONETE et al., 2013). Entretanto, espécies do gênero Eucalyptus são mais resistentes a níveis de acidez elevada (BARROS et al., 1990).

Analisando os valores médios encontrados para o fósforo $(\mathrm{P})$ foi considerado baixo, indicando a carência desse nutriente na área experimental (SILVEIRA et al., 1999). Esse resultado está de acordo com os valores encontrados por Hamid et al. (2015), onde relatam que 61\% dos solos do Pará apresentam teores de P abaixo de 6,6 $\mathrm{mg} \mathrm{dm}^{-3}$. Malavolta (1989), afirma que este elemento é imprescindível para as plantas, pois favorece o crescimento das raízes e a fotossíntese (SILVEIRA et al., 2004), auxiliando no desenvolvimento inicial. O fósforo é um dos elementos essenciais para planta e tem participação nas estruturas dos ácidos nucleicos, dos carboidratos, das membranas celulares, sendo que uma das principais deficiências causadas pela falta do fósforo é a clorose das folhas (SILVEIRA et al., 2004).

O Potássio (K) foi o nutriente primário que apresentou as maiores concentrações na área experimental 4,9 $\mathrm{mg} \mathrm{dm}^{-3}$. Esse elemento é essencial e tem alta demanda pelas plantas na fase inicial do seu desenvolvimento, superando muitas vezes até as demandas de N e P. Para Bellote et al. (1993), a elevada oferta deste nutriente no solo possibilita um maior suprimento das plantas e, por conseguinte, maiores ganhos em altura.

Os teores de enxofre (S) foram considerados médios, assim é necessária uma adequada elevação no nível desse elemento por ele ser um nutriente secundário importante, aliado a outros nutrientes como o nitrogênio no desenvolvimento dos vegetais. Segundo Sfredo et al. (2007), o S participa na formação estrutural dos vegetais, composição de alguns aminoácidos, está presente em todas as proteínas vegetais, inclusive enzimáticas e, indiretamente, está envolvido na formação da clorofila.

Os teores de Ca foram considerados altos, o que dentre outros fatores benéficos, pode corroborar para elevação do $\mathrm{pH}$ da área somado a um nível de calagem adequado. Esse nutriente apresenta grande relevância no crescimento inicial de plantas, pois atua na composição da parede celular, bem como está presente no processo fotossintético, na divisão de células, no movimento citoplasmático e aumento do volume celular (MALAVOLTA et al., 1997). O Ca é considerado como um dos nutrientes mais absorvido pela maioria das espécies florestais (BARROS et al., 1990; GOMES et al., 2008; LIMA et al., 2005). Em eucalipto esses teores de cálcio podem chegar a $75 \%$ na casca e no tronco e são exportados diretamente do solo a cada ciclo de corte (SIMONETE et al., 2013). 
A concentração de Mg no solo foi considerada baixa, o que pode ser um fator preocupante, já que teor de Ca foi considerado alto e quando a relação $\mathrm{Ca} / \mathrm{Mg}$ é muito grande, isso pode ser prejudicial para as plantas pela carência de Mg. Assim a calagem deve ser, prioritariamente, com a de calcário dolomítico, o qual pode elevar as taxas de reposição do $\mathrm{Mg}$ no solo. O Mg é conhecido pelo seu importante papel na formação de clorofila e na fotossíntese, assim como no estímulo ao crescimento de raízes e sementes (VALE, 2015). Sua deficiência é percebida no surgimento de folhas amareladas o que diminui a pigmentação da clorofila e afeta diretamente a fotossíntese, o transporte de carboidratos, a respiração celular e as sínteses enzimáticas reduzindo o bom desenvolvimento das plantas (FAVARIN et al., 2012).

O micronutriente B apresentou uma concentração média, o que caracteriza esse solo com uma razoável concentração desse elemento na área experimental, podendo beneficiar as plantas. O boro é fundamental no desenvolvimento dos vegetais, sendo que sua falta ou excesso no solo tem ocasionado efeitos negativos em florestas implantadas (ROCHA FILHO et al., 1979).

A concentração de $\mathrm{Zn}$ foi alta e isso pode ser um fator benéfico, dentro dos limites tolerados para a espécie. O Zn é considerado o micronutriente mais limitante à produtividade das culturas no Brasil, sendo que os reflexos de sua deficiência são os distúrbios no metabolismo das auxinas, principalmente do ácido indol acético (AIA), fitormônio responsável pelo crescimento das plantas (ROMUALDO, 2008).

O Fe apresentou alta concentração no solo. Fageria et al. (1981), afirma que o Fe em concentrações baixas prejudica o bom desenvolvimento do sistema radicular, no entanto, ainda ressaltam que em elevadas concentrações solúveis, retarda o crescimento. O micronutriente está envolvido em vários processos primordiais para o vegetal, como a fixação de nitrogênio, respiração, fotossíntese, síntese de DNA e de hormônios (SAHRAWAT, 2004).

O Mn apresentou um nível alto no solo. Hernandes (2009), afirma que esse nutriente está presente em vários processos metabólicos dos vegetais, como na ativação e constituição de enzimas, bem como na fotólise da água dentro dos cloroplastos. É um micronutriente que em falta prejudica o crescimento, desenvolvendo assim sintomas característicos de deficiência (VELOSO et al., 1995).

O micronutriente $\mathrm{Cu}$, apresentou nível médio na área experimental. Segundo Taiz et al. (2004), o micronutriente é fundamental para o metabolismo das espécies vegetais, pois atua juntamente com enzimas no transporte de elétrons na cadeia respiratória e como cofator de diversas outras reações.

Embora as plantas necessitem em menores quantidades dos micronutrientes, esses são tão importantes quantos os macronutrientes. Sem os micronutrientes, os vegetais não completam funções importantes, pois participam principalmente das funções metabólicas na ativação das enzimas, síntese de proteínas, respiração, fotossíntese, estruturação celular, crescimento entre outras funções (LOPES, 1998).

\section{Análise de variância e comparação múltipla das médias}

$\mathrm{Na}$ análise de variância houve diferença significativa entre os tratamentos aplicados, na qual, observou-se na comparação múltipla das médias pelo teste SNK de significância, que todos os tratamentos 
que receberam adubação de macro e micronutrientes em níveis variados em porcentagem, superaram todas as médias para as variáveis analisadas, diâmetro do coleto, diâmetro de copa e altura total em comparação ao T1 (controle) que não recebeu adubação (0\%) (Tabela 3). Souza et al. (2013), encontraram em seu trabalho resultados semelhantes quando analisaram essas mesmas variáveis com adubação de NPK no grânulo em desenvolvimento inicial do Eucalyptus platyphylla no município de Ulianópolis, Sudeste paraense.

Tabela 3: Comparação múltipla das médias pelo teste SNK, para os tratamentos experimentais.

\begin{tabular}{llll}
\hline \hline Tratamento & D coleto $(\mathrm{mm})$ & $\mathrm{D} \mathrm{copa}(\mathrm{cm})$ & $\mathrm{Ht}(\mathrm{cm})$ \\
\hline 1 & $8,97 \mathrm{~b}$ & $74,75 \mathrm{c}$ & $87,05 \mathrm{~b}$ \\
2 & $11,98 \mathrm{a}$ & $86,75 \mathrm{bc}$ & $93,88 \mathrm{ab}$ \\
3 & $14,82 \mathrm{a}$ & $94,09 \mathrm{ab}$ & $110,5 \mathrm{a}$ \\
4 & $15,51 \mathrm{a}$ & $105,19 \mathrm{a}$ & $113,19 \mathrm{a}$ \\
5 & $12,4 \mathrm{a}$ & $85,22 \mathrm{bc}$ & $95,88 \mathrm{ab}$ \\
6 & $12,51 \mathrm{a}$ & $85,09 \mathrm{bc}$ & $101,75 \mathrm{ab}$ \\
\hline Média & 12,55 & 87,97 & 99,84 \\
\hline Peso & 0,13 & 0,88 & 1,00 \\
\hline \hline
\end{tabular}

* Médias seguidas de mesma letra não diferem estatisticamente pelo teste SNK no nível de 5\% de significância.

Analisando os valores médios para o diâmetro do coleto, é notório que todos os tratamentos que receberam adubação não apresentaram diferença significativa entre si. Resultado semelhante a este pode ser observado no trabalho de Belapart et al. (2013), que avaliando o efeito de doses de $\mathrm{N}$ e Ca sobre o crescimento inicial do Guanandi (Calophyllum brasiliense Camb.) Constataram que apesar de aplicar diferentes doses de $\mathrm{N}$, os resultados de diâmetro do coleto não mostraram diferenças significativas. O único tratamento que diferiu significativamente dos demais foi o T1 (controle, $0 \%$ de adubação) ficando com a menor média $8,97 \mathrm{~mm}$. Essa diferença ocorreu pela falta de adubação no tratamento controle, principalmente de NPK que é requerido em altas demandas pelo eucalipto nesse estágio inicial de desenvolvimento e crescimento (PINTO et al., 2011). O diâmetro do coleto é uma variável que oferece a maior correlação com a sobrevivência de mudas a campo, um nível nutricional adequado aumenta a robustez do coleto, evita tortuosidade, quebra e tombamento, e o seu bom estado é um fator que determina a qualidade das mudas (CARNEIRO, 1995).

Para o diâmetro de copa, os tratamentos T2 (50\% de adubação), T5 (125\% de adubação), e T6 (150\% de adubação) não se diferenciaram significativamente, onde podemos relacionar esses níveis de adubação com a curva de crescimento e resposta nutricional nos níveis abaixo T2, e excessivos T5 e T6, sendo inadequados para o híbrido em análise. Já o T4 (100\% de adubação) obteve a maior média 105,19 cm, mas não diferindo estatisticamente do T3 (75\% de adubação) $94,09 \mathrm{~cm}$ de média. Barros et al. (2005) afirmam que o maior acúmulo de nutrientes no eucalipto na fase juvenil é nas folhas e nos galhos mais finos o que proporciona a formação e o fechamento de copa que é um dos fatores que permite um bom desenvolvimento da planta.

Para a altura total não houve diferença significativa entre o T3 (75\% de adubação) e o T4 (100\% de adubação), obtendo as maiores médias $110,5 \mathrm{~cm}$ e $113,19 \mathrm{~cm}$ e os melhores resultados, respectivamente. Essas médias foram superiores as encontradas no trabalho de Matos et al. (2012), em que a maior média de altura foi de $96 \mathrm{~cm}$, sob avaliação de cinco clones de eucalipto em desenvolvimento inicial e estado 
nutricional. Nos tratamentos T2 (50\% de adubação), T5 (125\% de adubação), e T6 (150\% de adubação) também não houve diferença significativa em altura, assim como na variável o diâmetro de copa e diâmetro de coleto para esses mesmos tratamentos.

Analisando as figuras abaixo (Figura 30), as doses crescentes de adubação em T2 e T3 ficaram abaixo da produção para o híbrido em questão durante o período da avaliação, sendo o T4 (100\% de adubação) o que melhor respondeu a relação nível de adubação obtendo as maiores médias entre todos os tratamentos para todas as variáveis. Já para os tratamentos T5 e T6 com maiores dosagens de adubação os resultados das médias foram inferiores para todas as variáveis em relação ao T4. Isso pode ser causado pelo efeito depreciativo, que é quando a cultura alcançou a sua máxima produção nas condições que está sendo cultivada, mas continua recebendo adubação, até exceder e se tornar fitotóxico provocando o declínio da produção (SILVA et al., 2007).

Os tratamentos T5 e T6 que receberam adubações superiores 125\% e 150\%, respectivamente, não responderam de forma positiva, sendo superados até pelas médias do T3 de adubação a 75\%, o que indica a não recomendação desses níveis de adubação para o híbrido Eucalyptus brassiana S.T. Blake X Eucalyptus grandis W. Hill ex Maiden. Para Silveira et al. (2004), fontes de fósforo como NPK (10-27-10), utilizado na primeira adubação, induzem a formação de um maior volume de sistema radicular, o que possibilita um melhor desenvolvimento inicial da cultura.

\section{Taxa de crescimento}

Considerando os valores de coeficiente angular de cada tratamento, o T1 obteve os menores valores de coeficientes em relação aos demais, para todas as variáveis analisadas (Figura 1). Com isso, esse tratamento apresentou as menores taxas de crescimento, uma vez que o coeficiente angular é diretamente proporcional a taxa de crescimento. Bassaco et al. (2014), em seu experimento com fósforo em híbridos de Eucalyptus grandis X Eucalyptus urophylla, observaram resultados semelhante em relação ao tratamento testemunha, que mostrou os menores valores de diâmetro e altura.

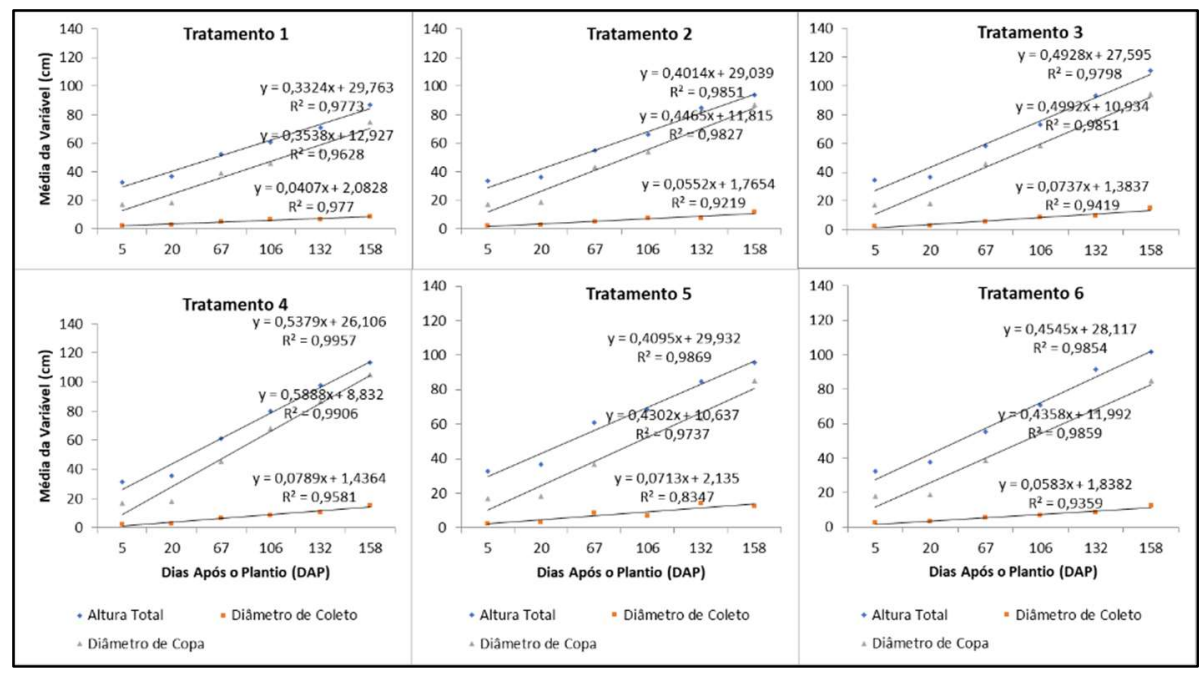

Figura 1: Taxa de crescimento em altura, diâmetro do coleto e diâmetro de copa para os seis tratamentos testados. 
O T4 foi o que obteve a maior taxa de crescimento em todas as variáveis analisadas entre todos os tratamentos, com coeficientes angulares de 0,5379; 0, 0789 e 0, 5888 para as variáveis altura, diâmetro do coleto e diâmetro de copa, respectivamente. O T3 apresentou as segundas maiores taxas de crescimento, com coeficiente angular de 0,4928 para altura, 0, 0737 para o diâmetro do coleto e 0, 4992 para o diâmetro de copa.

O fato desses tratamentos terem se destacado com as melhores taxas de crescimento diz respeito à aplicação recomendável de macro e micronutrientes no solo para um crescimento bom do eucalipto para as condições desse estudo. Gonçalves et al. (1995), diz que, na maioria das vezes, o solo não é capaz de fornecer em quantidades adequadas os nutrientes que o vegetal necessita para ter uma boa produtividade, necessitando de adubação para então apresentar um crescimento significativo.

Analisando a variável altura apenas entre os tratamentos T2, T5 e T6, observou-se que este último apresentou a maior taxa de crescimento entre os três, pois obteve um coeficiente angular de 0,45 , seguido pelo T5 com um coeficiente angular de 0,41 e por fim o T2 com 0, 40 de coeficiente. Analisando o diâmetro do coleto entre T2, T5 e T6 apenas, o T5 obteve a maior taxa de crescimento entre os três relacionados, com um coeficiente angular de 0, 07, seguido por T6 com 0, 06 e por fim T2 com 0, 05. Já para o diâmetro de copa, o T2 obteve a maior taxa de crescimento entre T5 e T6, com um coeficiente angular de 0,45 , seguido pelo T6 com 0, 44 e por último o T5 com 0, 43.

O T5 e T6, apesar de apresentarem maiores níveis de adubação, foram os que obtiveram baixas taxas de crescimento levando em consideração T3 e T4. Esse comportamento pode ser explicado pela lei do excesso de adubação, exemplificado por Silva et al. (2007), em que o excesso de nutrientes pode também prejudicar a produção das plantas, pois o acréscimo de nutrientes após o nível máximo, pode ocasionar um efeito depreciativo à produção. Resultados semelhantes podem ser observados no trabalho de Somavilla et al. (2014), que avaliando morfologicamente mudas de cedro australiano sob diferentes doses do fertilizante osmocote plus, verificou que até a dose de $7,9 \mathrm{~kg} \mathrm{~m}^{-3}$ de substrato, as plântulas apresentaram acréscimos em altura e diâmetro, porém quando submetidas a doses maiores do fertilizante apresentaram perdas no incremento da muda.

As baixas taxas de crescimento apresentadas no T2 podem ser explicadas pela lei do mínimo de Liebig, que revela que o crescimento é limitado pelo nutriente que estiver em menor disponibilidade, mesmo que os outros estejam em níveis adequados. A manutenção de elevadas taxas de crescimento requer adequada suplementação nutricional, mesmo em condições de disponibilidade hídrica elevada (SILVA, 2006).

\section{Ganho em produtividade}

O plantio apresentou crescimento em todos os níveis de adubação testados, quando comparados ao tratamento sem adubação (Tabela 4). 
Tabela 4: Ganhos em porcentagem de cada tratamento sob diferentes níveis de adubação.

\begin{tabular}{lllllll}
\hline \hline \multirow{2}{*}{ Tratamento } & $\mathrm{HT}$ & \multicolumn{3}{c}{$\mathrm{D} \mathrm{Col}}$. & $\mathrm{D}$ copa \\
\cline { 2 - 7 } & $\mathrm{cm}$ & $\%$ & $\mathrm{~mm}$ & $\%$ & $\mathrm{~cm}$ & $\%$ \\
\hline 1 & 0 & $0 \%$ & 0 & $0 \%$ & 0 & $0 \%$ \\
2 & 6,83 & $8 \%$ & 3,01 & $3 \%$ & 12 & $14 \%$ \\
3 & 23,45 & $27 \%$ & 5,85 & $7 \%$ & 19,34 & $22 \%$ \\
4 & 26,14 & $30 \%$ & 6,54 & $8 \%$ & 30,44 & $35 \%$ \\
5 & 8,83 & $10 \%$ & 3,42 & $4 \%$ & 10,47 & $12 \%$ \\
6 & 14,7 & $17 \%$ & 3,54 & $4 \%$ & 10,34 & $12 \%$ \\
\hline \hline
\end{tabular}

Em que: Altura total (HT); Diâmetro do coleto (D Col.); Diâmetro de copa (D Copa).

O T4 foi o que obteve maior ganho em altura (30\%), diâmetro do coleto $(8 \%)$ e diâmetro de copa (35\%). O T3 foi o segundo com melhores valores de ganhos para as mesmas variáveis. Estes resultados foram semelhantes aos da taxa de crescimentos especificados anteriormente. Bartieres et al. (2016), avaliando o desenvolvimento inicial, sobrevivência e composição nutricional das plantas através de testes com hidrogel, calagem e adubação em plantas híbridas de eucalipto, verificaram que seu melhor tratamento, obteve um ganho de $11,4 \%$ para altura em relação ao tratamento controle e $18 \%$ para o diâmetro em relação ao tratamento controle. É possível observar que os tratamentos T5 e T6 apresentaram os mesmos ganhos para as variáveis diâmetro do coleto e diâmetro de copa (4\% e 12 \% respectivamente), revelando que não obtiveram diferenças significativas para essas variáveis, logo não são recomendados.

\section{Doses máximas recalculadas}

Para calcular formulações de recomendação de adubação, inicia-se a partir da interpretação da análise do solo e os valores totais de nutrientes obtidos ou da análise do sistema solo x planta, relacionando os incrementos médios anuais às variáveis da cultura no período avaliado, e a recomendação é dada em kg ha $^{-1}$ (BARROS et al., 2005; SILVA, 2018).A partir disso, foram encontradas equações de regressão para expressar as doses máximas recalculadas de macro e micronutrientes com relação aos valores obtidos para cada variável correspondente e o valor da média ponderada para as variáveis (Tabela 5).

Tabela 5: Doses máximas recalculadas para os macros e micronutrientes para o híbrido Eucalyptus brassiana S.T. Blake X Eucalyptus grandis W. Hill ex Maiden, em Kg ha-1.

\begin{tabular}{lllll}
\hline \hline \multirow{2}{*}{ Nutriente } & \multicolumn{3}{l}{ Dose Máxima Recalculada $\left(\mathrm{kg} \mathrm{ha}^{-1}\right)$} & \\
\cline { 2 - 5 } & Diâmetro do Coleto & Diâmetro de Copa & Altura Total & Média Ponderada \\
\hline $\mathrm{N}$ & 289,50 & 174,21 & 207,30 & 197,95 \\
$\mathrm{P}$ & 55,76 & 51,59 & 57,58 & 54,83 \\
$\mathrm{~K}$ & 405,00 & 515,00 & 466,67 & 484,00 \\
$\mathrm{Ca}$ & 290,00 & 246,33 & 301,50 & 276,55 \\
$\mathrm{Mg}$ & 65,29 & 62,73 & 69,54 & 66,28 \\
$\mathrm{~S}$ & 23,44 & 21,92 & 24,31 & 23,21 \\
$\mathrm{~B}$ & 1,80 & 1,68 & 1,86 & 1,78 \\
$\mathrm{Cu}$ & 2,64 & 2,46 & 2,73 & 2,61 \\
$\mathrm{Zn}$ & 2,81 & 2,62 & 2,91 & 2,77 \\
\hline \hline
\end{tabular}

Em que: N - Nitrogênio, P- Fósforo, K- Potássio, Ca- Cálcio; Mg- Magnésio, S- Enxofre, B- Boro, Cu - Cobre, Zn- Zinco.

A média ponderada que vai expressar o valor real de cada nutriente a ser recomendado pelas doses máximas recalculadas, ou seja, o valor recomendado de cada nutriente para o híbrido Eucalyptus brassiana S.T. Blake X Eucalyptus grandis W. Hill ex Maiden, em kg ha-1a ser aplicado na fase inicial de desenvolvimento, 
foi definida a partir das equações de regressão das funções quadráticas do tipo $Y=B_{0}-B_{1} X+B_{2} X^{2}$. A primeira derivada foi igualada a zero, em que a constante " $x$ " apresenta o sinal negativo e a variável é o $x^{2}$, para parábolas de concavidade voltada para baixo. Assim, os valores das doses máximas recalculadas para cada nutriente e para as variáveis foram obtidos através da derivação da equação quadrática: $X=\left(B_{1}\right) /\left(2 * B_{2}\right)$ (Tabela 6).

Tabela 6: Modelos quadráticos de equação de regressão ajustados para os macros e micronutrientes para o híbrido Eucalyptus brassiana S.T. Blake X Eucalyptus grandis W. Hill ex Maiden.

\begin{tabular}{|c|c|c|c|}
\hline Nutrientes & Variável & Equação de regressão & $\mathrm{R}^{2}$ \\
\hline & Diâmetro do coleto & $y=-0,0001 x^{2}+0,0579 x+8,7177$ & 0,81 \\
\hline \multirow[t]{3}{*}{$\mathrm{N}$} & Diâmetro de copa & $y=-0,0007 x^{2}+0,2439 x+73,285$ & 0,68 \\
\hline & Altura total & $y=-0,0005 x^{2}+0,2073 x+85,505$ & 0,58 \\
\hline & Diâmetro do coleto & $y=-0,0017 x^{2}+0,1896 x+8,8063$ & 0,74 \\
\hline \multirow[t]{3}{*}{$P$} & Diâmetro de copa & $y=-0,0078 x^{2}+0,8048 x+73,778$ & 0,62 \\
\hline & Altura total & $y=-0,0057 x^{2}+0,6564 x+86,25$ & 0,50 \\
\hline & Diâmetro do coleto & $y=-3 E-05 x^{2}+0,0243 x+8,8063$ & 0,74 \\
\hline \multirow[t]{3}{*}{ K } & Diâmetro de copa & $y=-0,0001 x^{2}+0,103 x+73,778$ & 0,62 \\
\hline & Altura total & $y=-9 E-05 x^{2}+0,084 x+86,25$ & 0,50 \\
\hline & Diâmetro do coleto & $y=-6 E-05 x^{2}+0,0348 x+8,8063$ & 0,74 \\
\hline \multirow[t]{3}{*}{$\mathrm{Ca}$} & Diâmetro de copa & $y=-0,0003 x^{2}+0,1478 x+73,778$ & 0,62 \\
\hline & Altura total & $y=-0,0002 x^{2}+0,1206 x+86,25$ & 0,50 \\
\hline & Diâmetro do coleto & $y=-0,0012 x^{2}+0,1567 x+8,8063$ & 0,74 \\
\hline \multirow[t]{3}{*}{$\mathrm{Mg}$} & Diâmetro de copa & $y=-0,0053 x^{2}+0,6649 x+73,778$ & 0,62 \\
\hline & Altura total & $y=-0,0039 x^{2}+0,5424 x+86,25$ & 0,50 \\
\hline & Diâmetro do coleto & $y=-0,0095 x^{2}+0,4453 x+8,8063$ & 0,74 \\
\hline \multirow[t]{3}{*}{$S$} & Diâmetro de copa & $y=-0,0431 x^{2}+1,8897 x+73,778$ & 0,62 \\
\hline & Altura total & $y=-0,0317 x^{2}+1,5415 x+86,25$ & 0,50 \\
\hline & Diâmetro do coleto & $y=-1,616 x^{2}+5,8197 x+8,8063$ & 0,74 \\
\hline \multirow[t]{3}{*}{ B } & Diâmetro de copa & $y=-7,3615 x^{2}+24,696 x+73,778$ & 0,62 \\
\hline & Altura total & $y=-5,4063 x^{2}+20,145 x+86,25$ & 0,50 \\
\hline & Diâmetro do coleto & $y=-0,7523 x^{2}+3,9709 x+8,8063$ & 0,74 \\
\hline \multirow[t]{3}{*}{$\mathrm{Cu}$} & Diâmetro de copa & $y=-3,4271 x^{2}+16,85 x+73,778$ & 0,62 \\
\hline & Altura total & $y=-2,5169 x^{2}+13,745 x+86,25$ & 0,50 \\
\hline & Diâmetro do coleto & $y=-0,6633 x^{2}+3,7286 x+8,8063$ & 0,74 \\
\hline \multirow[t]{2}{*}{$\mathrm{Zn}$} & Diâmetro de copa & $y=-3,0217 x^{2}+15,822 x+73,778$ & 0,62 \\
\hline & Altura total & $y=-2,2191 x^{2}+12,906 x+86,25$ & 0,50 \\
\hline
\end{tabular}

N - Nitrogênio, P - Fósforo, K - Potássio, Ca - Cálcio; Mg - Magnésio, S - Enxofre, B - Boro, Cu - Cobre, Zn - Zinco.

Este mesmo método do modelo quadrático também foi utilizado no trabalho de Scivittaro et al. (2004), para ajuste de dosagens de fertilizantes de liberação lenta e fertilizantes solúveis de $\mathrm{N}_{1} \mathrm{P}_{2} \mathrm{O}_{5}, \mathrm{~K}_{2} \mathrm{O}, \mathrm{Ca}$, $\mathrm{Mg}, \mathrm{S}, \mathrm{B}, \mathrm{Cu}, \mathrm{Fe}, \mathrm{Mn}, \mathrm{Zn}$ e Mo, em \% definidas para cada nutriente em um período de 180 dias, para as variáveis altura, diâmetro do coleto e matéria seca produzida por mudas do porta-enxerto 'Trifoliata' em tubete na casa de vegetação da Embrapa em Pelotas-RS. Esses ajustes são necessários para encontrar os valores máximos das dosagens de cada nutriente que visa proporcionar o melhor desenvolvimento da cultura.

Os valores dos macros e micronutrientes encontrados pelas doses recalculadas e pelas médias ponderadas das variáveis diâmetro do coleto, diâmetro de copa e altura total para o híbrido em estudo apresentaram a seguinte sequência de decrescimento $\mathrm{K}>\mathrm{Ca}>\mathrm{N}>\mathrm{Mg}>\mathrm{P}>\mathrm{S}>\mathrm{Zn}>\mathrm{Cu}>\mathrm{B}$. Essa tendência de ordem dos teores de nutrientes é analisada em muitos híbridos de eucalipto. Matos et al. (2012), 
trabalhando com clones de eucalipto, encontraram essa ordem $\mathrm{N}>\mathrm{K}>\mathrm{Ca}>\mathrm{Mg}>\mathrm{P}>\mathrm{Mn}>\mathrm{Fe}>\mathrm{Zn}>\mathrm{Cu}$, nas médias dos nutrientes em concentrações foliares aos 18 meses de idade no nordeste do Pará. Fica clara, portanto a importância da resposta do eucalipto à nutrição com N, K e Ca nesses cultivos. Essas ordens decrescentes divergiram da encontrada por Consensa (2017), ao avaliar um povoamento de Eucalyptus saligna com 7 anos de idade, por extração dos nutrientes em compartimentos da árvore, em que apresentou seguinte ordem $\mathrm{Ca}>\mathrm{N}>\mathrm{K}>\mathrm{Mg}>\mathrm{S}>\mathrm{P}>\mathrm{Mn}>\mathrm{Fe}>\mathrm{Zn}>\mathrm{B}>\mathrm{Cu}$. Essas variações na comparação da ordem demandas dos nutrientes podem ser explicadas pelas idades e por ser em híbridos de espécies diferentes.

No trabalho de Oliveira (2017), com 4 clones (E.urophylla x E. sp.; E. grandis x E. camaldulensis; E. urophylla e; E. urophylla $\times$ E. tereticornis), analisando o crescimento, eficiência nutricional, no que tange à demanda na utilização de nutrientes, cultivados em três regiões de Minas Gerais, esse autor encontrou diferentes níveis de demanda por nutriente e eficiência nutricional para cada clone por compartimento da árvore, tronco, lenho casca, área foliar, o que se pode afirmar que essa ordem de acúmulo dos nutrientes foi influenciada pela interação entre o genótipo e o ambiente.

Silva (2013), em seu trabalho com três tipos de clones de eucalipto cultivados na região de Três Marias no Estado de Minas Gerais, avaliando a produtividade, demanda e eficiência nutricional aos 84 meses de idade, encontrou o conteúdo nutricional médio dos macronutrientes nos compartimento das árvores em $\mathrm{kg} \mathrm{ha}^{-1}$, na ordem decrescente a seguir: Clone GG 50: $\mathrm{N}=921,32>\mathrm{K}=498,88>\mathrm{Ca}=403,19>\mathrm{Mg}=117,55>$ $\mathrm{S}=79,76>\mathrm{P}=42,55$.; Clone GG 100: $\mathrm{K}=520,59>\mathrm{N}=513,44>\mathrm{Ca}=246,68>\mathrm{Mg}=52,72>\mathrm{P}=52,48>\mathrm{S}=47,59$; Clone GG 157: $\mathrm{N}=449,56>\mathrm{Ca}=410,05>\mathrm{K}=370,43>\mathrm{P}=79,12>\mathrm{Mg}=56,14>\mathrm{S}=51,68$. Os valores de $\mathrm{P}>$ $\mathrm{Ca}>\mathrm{Mg}$, para os três clones se aproximaram proporcionalmente com os valores encontrados das doses máximas calculadas para esses nutrientes. Já os valores de $\mathrm{N}>\mathrm{K}>\mathrm{S}$ foram bem superiores aos valores encontrados das doses máximas calculadas na presente pesquisa.

Nesse sentido, várias literaturas mostram que as demandas por absorção de nutrientes estão relacionadas, principalmente, às características das espécies, local de origem, material genético, fatores ambientais e regionais (solo, clima) onde são cultivadas, sendo a eficiência na utilização dos nutrientes relacionada às variáveis de estágios de desenvolvimento das plantas, idade do plantio, oferta de nutrientes (solo e adubação) e funções que os nutrientes exercem nos compartimentos da cultura como: tronco, lenho, copa e raízes distribuídos ao longo do ciclo vegetativo (BARROS et al., 1990, 2005; BELLOTE et al., 1993; GONÇALVES et al., 1995; LIMA et al., 2005; SOUZA et al., 2013; SILVA, 2018; SILVEIRA et al., 2000).

Assim, como cada novo material genético desenvolvido de eucalipto, tende a ter habilidades de adaptação ambiental e demandas diferenciadas de uso dos nutrientes do solo e na adubação, existindo assim grande diferenciação quanto à eficiência de absorção e utilização dos nutrientes, devem ser testados por experimentos antes do material ser implantado em escala comercial, levando-se em consideração as peculiaridades de todas as regiões do Brasil, visando atender a máxima produção (OLIVEIRA, 2017; SILVA et al., 2012; SILVA, 2013).

Nesse contexto, estudos posteriores são necessários para que se acompanhe o crescimento e 
desenvolvimento do híbrido Eucalyptus brassiana S.T. Blake X Eucalyptus grandis W. Hill ex Maiden e assim complementar a avaliação da eficiência nutricional da máxima produção em escala comercial.

\section{CONCLUSÕES}

O híbrido Eucalyptus brassiana S.T. Blake X Eucalyptus grandis W. Hill ex Maiden, apresentou desenvolvimento inicial diferenciado entre os níveis de adubação testados. Dos cinco níveis de adubação avaliados as melhores respostas foram para os tratamentos 3 ( $75 \%$ de adubação) e 4 (100\% de adubação). 0 tratamento 4 apresentou as melhores taxas de crescimento e ganho de produtividade em até $35 \%$. Os valores encontrados de macro e micronutrientes para proporcionar a máxima produção do híbrido Eucalyptus brassiana S.T. Blake X Eucalyptus grandis W. Hill ex Maiden foram em ordem decrescente de nutrientes $\mathrm{K}=$ $484,00>\mathrm{Ca}=276,75>\mathrm{N}=197,95>\mathrm{Mg}=66,28>\mathrm{P}=54,83>\mathrm{S}=23,21>\mathrm{Zn}=2,77>\mathrm{Cu}=2,61>\mathrm{B}=1,78 \mathrm{em} \mathrm{kg}$ $\mathrm{ha}^{-1}$.

\section{REFERÊNCIAS}

ALVARES, C. A.; STAPE, J. L.; SENTELHAS, P. C.; GONÇALVES, J. L. M.; SPAROVEK, G.. Köppen's climate classification map for Brazil. Meteorologische Zeitschrift, v.22, n.6, p.711-728, 2013. DOI: http://doi.org/10.1127/0941-2948/2013/0507

ANDA. Associação Nacional para Difusão de Adubos. Fertilizantes e o seu uso eficiente. ANDA, 2017.

BANDEIRA, R. S.; DIAS, T. S.. Estado nutricional de plantios clonais de híbrido de Eucalyptus urophylla x Eucalyptus brassiana S.T. Blake, na mesorregião sudeste do estado do Pará. Monografia (Bacharelado em Engenharia Florestal) Universidade Federal Rural da Amazônia, Paragominas, 2016.

BARROS, N. F.; NOVAIS, R. F.; NEVES, J. C. L.. Fertilidade de solos, nutrientes e produção florestal. Visão agrícola, n.4, p.76-79, 2005.

BARROS, N. F.; NOVAIS, R. F.; NEVES, J. C. L.. Fertilização e correção do solo para o plantio de eucalipto. In: BARROS, N. F.; NOVAIS, R. F.. Relação solo-eucalipto. Viçosa: Folha de Viçosa, 1990. p.127-186.

BARTIERES, E. M. M.; CARNEVALI, N. H. S.; LIMA, E. S.; CARNEVALI, T. O.; MALLMENN, V.. Hidrogel, calagem e adubação no desenvolvimento inicial, sobrevivência e composição nutricional de plantas hibridas de eucalipto. Pesquisa florestal brasileira, Colombo, v.36, n.86, p.145152, 2016.

BASSACO, M. V. M.; WALCZAK, A.. Crescimento inicial do híbrido Eucalyptus urograndis sob diferentes doses de fósforo e gesso agrícola no município de Jaguariaíva/PR. Revista da União Latino-americana de Tecnologia, Jaguariaíva, v.2, p.78-96, 2014.

BELAPART, D.; LEITE, S. M. M.; GIROTTO, M. D.; PEDRONE, L. P.. Efeito de diferentes doses de nitrogênio e cálcio no desenvolvimento inicial do guanandi. Unimar ciências, v.22, n.1-2, p.71-77, 2013.
BELLOTE, A. F. J.; FERREIRA, C. A.. Nutrientes Minerais e Crescimento de Árvores Adubadas de Eucalyptus grandis, na Região do Cerrado, no Estado de São Paulo. Boletim de Pesquisa Florestal, Colombo, n.26/27, p.17-28, 1993.

CARNEIRO, J. G. A.. Produção e controle de qualidade de mudas florestais. Curitiba: UFPR, 1995.

CIPRIANI, N. H.; VIEIRA, A. H.; MENDES, A. M.; MARCOLAN, A. L.. Há sempre resposta à adubação de manutenção do eucalipto?: Um estudo de caso em Porto Velho(RO). EMBRAPA, 2015.

CONSENSA, C. B.. Implicações silviculturais da colheita da biomassa e da remoção de nutrientes de um povoamento de Eucaliptus saligna. Tese (Doutorado em Engenharia Florestal) - Universidade Federal de Santa Maria, Santa Maria, 2017.

FAGERIA, N. K.; FILHO, M. P. B.; CARVALHO, J. R. P.. Influência de ferro no crescimento e na absorção de $\mathrm{P}, \mathrm{K}, \mathrm{Ca}$ e Mg pela planta de arroz em solução nutritiva. Pesquisa agropecuária, Brasília, p.483-488, 1981.

FAVARIN, J. L.; NETO, A. P.; TEZOTTO, T.; MARTINS, P. O.; TEIXEIRA P. P. C.. Correção do magnésio no solo é essencial ao cafeeiro, lavoura em desenvolvimento: rocha calcária é principal fonte de magnésio para correção de acidez do solo. Jacuí, 2012.

FILIZOLA, H. F.; GOMES, M. A. F.; SOUZA, M. D.. Manual de procedimentos de coleta de amostras em áreas agrícolas para análise da qualidade ambiental: solo, água e sedimentos. Jaguariúna: Embrapa Meio Ambiente, 2006.

GOMES, K. C. O.; PAIVA, H. N.; NEVES, J. C. L.; BARROS, N. F.; SILVA, S. R.. Crescimento de mudas de garapa em resposta à calagem e ao fósforo. Revista Árvore, Viçosa, v.32, n.3, p.387-394, 2008 
GONÇALVES, J. L. M.. Recomendações de adubação para Eucalyptus e Pinus e espécies típicas da Mata Atlântica. Documentos Florestais. Piracicaba (15), p. 1 -15. 1995.

HAMID, S. S.; SOUZA, E. S.; TEIXEIRA, R. A.; OLIVEIRA, F. J.; FERNANDES, A. R.. Teores naturais totais e disponíveis de fósforo em Latossolos do Estado do Pará. In: CONGRESSO BRASILEIRO DE CIÊNCIA DO SOLO. Anais. Natal, 2015.

HERNANDES, A.. Influência do manganês no crescimento e na composição mineral de mudas de caramboleira. Dissertação (Mestrado em Ciência do Solo) - Universidade Estadual Paulista, Jaboticabal, 2009.

IBÁ. Industria Brasileira de Árvores. Relatório 2018. Industria Brasileira de Árvores, 2019.

LIMA, A. M. N.; NEVES, J. C. L.; SILVA, I. R.; LEITE, F. P.. Cinética de absorção e eficiência nutricional de $\mathrm{K}, \mathrm{Ca}$ e $\mathrm{Mg}$ em plantas jovens de quatro clones de eucalipto. Revista Brasileira de Ciências do Solo, v.29, n.6, p.903-909, 2005.

MALAVOLTA, E.. ABC da Adubação. São Paulo: Agronômica Ceres, 1989.

MALAVOLTA, E.; VITTI, G. C.; OLIVEIRA, S. A.. Avaliação do estado nutricional das plantas, princípio e aplicações. 2 ed. Piracicaba: POTAFOS, 1997.

LOPES, A. S.. Manual Internacional de Fertilidade do Solo. 2 ed. Piracicaba: POTAFOS, 1998.

MATOS, G. S. B.; SILVA, G. R. S.; GAMA, M. A. P.; VALE, R. S.; ROCHA, J. E. C.. Desenvolvimento inicial e estado nutricional de Clones de eucalipto no nordeste do Pará. Acta Amazonica, v.42, n.4, p.491- 500, 2012.

NEVES, J. C. L.. Produção e partição de biomassa, aspectos nutricionais e híbridos em plantios clonais de eucalipto na região litorânea do Espírito Santo. Rio de Janeiro: Universidade Estadual do Norte Fluminense, 2000.

OLIVEIRA, J. R.. Crescimento, produção e eficiência nutricional de genótipos de eucalipto em diferentes condições edafoclimáticas de Minas Gerais. Tese (Doutorado em Solos e Nutrição de Plantas) Universidade Federal de Viçosa, Viçosa, 2017.

PINTO, S. I. C.; NETO, A. E. F.; NEVES, J. C. L.; FAQUIN, V.; MORETTI, B. S.. Eficiência nutricional de clones de eucalipto na fase de mudas cultivados em solução nutritiva. Revista Brasileira de Ciências Solo, Lavras, v.35, p.523-533, 2011.

ROCHA FILHO, J. V. C. R.; HAAG, H. P.; OLIVEIRA, G. D.; SARRUGE, J. R.. Influência do boro no crescimento e na composição química de Eucalyptus grandis. Anais da Escola Superior Agricultura "Luiz de Queiroz", São Paulo, v.36, p.139-151, 1979.

ROMUALDO, L. M.. Modos de aplicação de zinco no crescimento inicial de plantas de milho e de sorgo em casa de vegetação. Dissertação (Mestrado em Produção Vegetal) - Universidade Estadual Paulista, Jaboticabal, 2008.
SAHRAWAT, K. L.. Iron toxicity in wetland rice and the role of other nutrients. Journal of Plant Nutrition, New York, v.27, n.8, p.1471-1504, 2004.

SAINANE, K. L.. Dealing with non-normal date. Physical Medicine and Rehabilitation, v.4, n.12, p.1001-1005, 2012.

SANA, R. S.; ANGHINONI, I.; BRANDÃO, Z. N.; HOLZSCHUH, M. J.. Variabilidade espacial de atributos físico-químicos do solo e seus efeitos na produtividade do algodoeiro. Rev. Bras. Eng. Agríc. Ambienteal. v.18, n.10, p.994-100, 2014.

SANTANA, R. C.; BARROS, N. F.; NEVES, J. C. L.. Eficiência de utilização de nutrientes e sustentabilidade da produção em procedências de Eucalyptus grandis $x$ Eucalyptus saligna em sítios florestais do Estado de São Paulo. Revista Árvore, Viçosa, v.26, n.4, p.447-457, 2002.

SANTOS, A. L. C.; SILVA, J. O.. Avaliação econômica de um plantio clonal de Eucalyptus sp para produção de celulose na mesorregião sudeste paraense. Trabalho de Conclusão de Curso (Graduação) - Universidade Federal Rural da Amazônia, Paragominas, 2016.

SANTOS, H. G.; JACOMINE, P. K. T.; ANJOS, L. H. C.; OLIVEIRA, V. A.; LUMBRERAS, J. F.; COELHO, M. R.; ALMEIDA, J. A.; ARAÚJO FILHO, J. C.; OLIVEIRA, J. B.; CUNHA, T. J. F.. Sistema brasileiro de classificação de solos. 5 ed. Brasília: Embrapa, 2018.

SCIVITTARO, W. B.; OLIVEIRA, R. P.; RADMANN, E. B.. Doses de fertilizante de liberação lenta na formação do portaenxerto 'trifoliata'. Rev. Bras. Frutic, Jaboticabal, v.26, n.3, p.520-523, 2004

SFREDO, G. J.; LANTMANN, Á. F.. Enxofre Nutriente necessário para maiores rendimentos da soja. Londrina: EMBRAPA, 2007.

SILVA, G. G. C.. Nutrição, crescimento e sua modelagem em povoamento de eucalipto em resposta à disponibilidade de água e nutrientes. Tese (Doutorado em Solos e Nutrição de plantas) - Universidade Federal de Viçosa, Viçosa, 2006.

SILVA, J. S. O.; SILVA FILHO, J. B.; RESENDE, P. L.. Aplicação Econômica de Adubos. Viçosa: CTP, 2007.

SILVA, M. O. P; CORRÊA, G. F; COELHO, L.; RABELO, P. G.. Avaliação de dois tratamentos de adubação em plantio de eucalipto clonal em solo arenoso. Biosci. J., Uberlândia, v.28, n.1, p.212-222, 2012.

SILVA, N. F.. Produtividade, demanda e eficiência nutricional de clones de eucalipto em regime de alto fuste e talhadia. Dissertação (Mestrado em Solo e Nutrição de Plantas) - Universidade Federal de Viçosa, Viçosa, 2013.

SILVA, S. B.. Análise de Solos Para Ciências Agrárias. 2 ed Belém: Universidade Federal Rural da Amazônia, 2018.

SILVEIRA, R. L. V. A.; GAVA, J. L.. Nutrição e Adubação Fosfatada em Eucalyptus. In: YAMADA, T.; ABDALLA, S. R. S.. Fósforo na Agricultura Brasileira. Piracicaba: Potafós, 2004.

SILVEIRA, R. L. V. A.; HIGASHI, E. N.; GONÇALVES, A. N.; MOREIRA, A.. Avaliação do estado nutricional do Eucalyptus: 
diagnose visual, foliar e suas interpretações (compact disc). In: SIMPÓSIO SOBRE FERTILIZAÇÃO E NUTRIÇÃO FLORESTAL, Anais. Piracicaba, 1999.

SILVEIRA, R. L. V. A.; MALAVOLTA, E.. Nutrição e adubação potássica em Eucalyptus. Potafos - encarte técnico. Informações agronômicas no 91. Piracicaba, 2000.

SIMONETE, M. A., CHAVES D. M., TEIXEIRA, C. F. A., MORO, L.; NEVES, C. U.. Fornecimento de cálcio para plantas de Eucalyptus saligna por meio de aplicação de resíduo industrial lama de cal. Revista Brasileira de Ciência do Solo, v.37, p.1343-1351, 2013.

SOMAVILLA, A.; CANTARELLI, E. B.; MARIANO, L. G.; ORTIGARA, C.; LUZ, F. B.. Avaliações morfológicas de mudas de Cedro australiano submetidas a diferentes doses do fertilizante osmocote plus. Comunicata Scientiae, Bom Jesus, v.5, n.4, p.493-498, 2014.
SOUZA, A. B.; GAMA, M. A. P.; ROCHA, J. E. C.; CABRERA, E.; TEIXEIRA, S. C.; CUNHA, L.. Desenvolvimento inicial de Eucalipto em função da fertilização com adubo NPK no grânulo, Amazônia Oriental. In: CONGRESSO BRASILEIRO DE CIÊNCIA DO SOLO. Anais. 2013.

TAIZ, L.; ZEIGER, E.. Fisiologia Vegetal. 3 ed. Porto Alegre: Artmed, 2014.

VALE, F.. Magnésio: Importância e necessidades. Informativo Técnico. Adubai Consultoria, 2015.

VELOSO, C. A. C.; MURAOKA, T.; MALAVOLTA, E.; CARVALHO, J. G.. Influência do manganês sobre a nutrição mineral e crescimento da pimenteira do reino (Piper nigrum, L.). Sci. Agric., Piracicaba, v.52, n.2, p.376-383, 1995.

A CBPC - Companhia Brasileira de Produção Científica (CNPJ: 11.221.422/0001-03) detém os direitos materiais desta publicação. Os direitos referem-se à publicação do trabalho em qualquer parte do mundo, incluindo os direitos às renovações, expansões e disseminações da contribuição, bem como outros direitos subsidiários. Todos os trabalhos publicados eletronicamente poderão posteriormente ser publicados em coletâneas impressas sob coordenação da Sustenere Publishing, da Companhia Brasileira de Produção Científica e seus parceiros autorizados. Os (as) autores (as) preservam os direitos autorais, mas não têm permissão para a publicação da contribuição em outro meio, impresso ou digital, em português ou em tradução. 